\title{
Drug use and pulmonary death rates in increasingly symptomatic asthma patients in the UK
}

Christoph R Meier, Hershel Jick

\begin{abstract}
Background - There is concern about an increase in deaths from respiratory causes in asthma patients using long acting $\beta$ agonists. According to the guidelines of the British Thoracic Society, long acting $\beta$ agonists, ipratropium bromide, and theophylline should be used to treat patients with increasing asthma severity who are already receiving treatment with short acting $\beta$ agonists and inhaled steroids. A study was therefore undertaken to compare the characteristics and short term respiratory mortality rates in first time users of one of these three drugs.
\end{abstract}

Methods - An open cohort study with a nested case-control analysis was performed on the UK based General Practice Research Database (GPRD). First time users of either salmeterol $(n=8386)$, ipratropium bromide $(n=4305)$, or theophylline $(n=4228)$ between 1 January 1992 and 30 April 1995 were identified and followed for 16 weeks. Drug usage patterns, predictors for respiratory mortality, and the number of deaths at 16 weeks in the three drug groups were compared.

Results - The three asthma drugs were most often prescribed to patients with severe asthma. Age, a concomitant diagnosis of chronic obstructive pulmonary disease or emphysema, number of asthma drug prescriptions, number of visits to the general practitioner, and whether or not the patient had been admitted to hospital due to the respiratory disease in the 12 months prior to the start of the new drug therapy were strong predictors for asthma mortality. After adjusting for several risk factors, the relative risk estimates of a respiratory death for ipratropium bromide and theophylline users compared with salmeterol users were 1.8 (95\% CI 0.4 to 9.6$)$ and 3.0 (95\% CI 0.4 to 22.4$)$, respectively. Conclusions - In the UK population studied, salmeterol, ipratropium bromide and theophylline are regularly used to treat patients with asthma of increasing severity. Salmeterol use was not associated with an increase in short term mortality compared with ipratropium bromide and theophylline.

(Thorax 1997;52:612-617)

Keywords: salmeterol, asthma, respiratory disease, death.
There is currently concern about the short term risk of adverse outcomes, particularly death, in patients with increasing asthma severity who are started on additional asthma therapy. ${ }^{1-3}$ An observational study based on the General Practice Research Database (GPRD) was therefore performed to examine the use of drugs recommended for increasingly symptomatic asthma patients and to estimate the short term pulmonary death rates in this population in relation to the last prescribed asthma drug. According to the recommendations of the British Thoracic Society ${ }^{4}$ the long acting $\beta$ agonist salmeterol, the anticholinergic agent ipratropium bromide, and the methylxanthine derivative theophylline are indicated for the treatment of patients with asthma of increasing severity, and only in addition to a short acting bronchodilator or an inhaled corticosteroid (steps 3 and 4 on the treatment scale). Assuming that these recommendations were regularly followed, we studied patients with a diagnosis of asthma for a period of 16 weeks after they had received a first time prescription for one or more of these drugs ${ }^{1}$ and compared the characteristics of users and mortality in these three cohorts.

\section{Methods}

Over four million people in the UK are enrolled with selected general practitioners who use office computers provided by Value Added Medical Products and who have agreed to provide data for research purposes. The General Practice Research Database (GPRD) is owned by the UK health departments. General practitioners have been trained to record medical information in a standard manner and to supply it anonymously. The information recorded includes demographic data, medical diagnoses, details of stays in hospital, and deaths. The doctors generate prescriptions directly with the computer, and this prescription information is automatically transcribed into the computer record. Death certificates and necropsy findings (when conducted) are available for review. A modification of the Oxford Medical Information System classification is used to enter medical diagnoses, and a coded drug dictionary based on the UK Prescription Pricing Authority's dictionary is used for the recording of prescriptions. The recorded information on drug exposure, diagnoses, and deaths in the GPRD is of high quality and is satisfactory for drug safety studies. ${ }^{5-8}$ 
Recording of deaths is virtually complete in the GPRD. The annual death rate derived from this database is 10.8 and 10.5 per 1000 people actively enrolled in 1992 and 1993, respectively. These rates are closely similar to the rate of 11.0 per 1000 derived from available UK data. ${ }^{9}$

\section{STUDY COHORTS AND ASSESSMENT OF}

MORTALITY RATES

From the computer-recorded clinical records we identified all persons aged $12-64$ years with a diagnosis of asthma who received a first time prescription for salmeterol, ipratropium bromide (including the nebulised form), or theophylline (or aminophylline) between 1 January 1992 and 30 April 1995. Subjects had to have a computer-recorded prescription history of at least six months' duration prior to the index date (the date of first prescription) in order to be eligible to participate in the study. Patients with a diagnosis of cystic fibrosis were excluded from the study population.

The study patients were followed for exactly 112 days ( 16 weeks) after receiving a first prescription for one of the three study drugs of interest and all deaths which occurred in this time period were identified. We distinguished between respiratory deaths, deaths from cardiovascular diseases, cancer deaths, and deaths from other causes, and death certificates for patients who had died from respiratory and cardiovascular diseases were examined individually. If a patient had more than one primary cause of death on the death certificate the respiratory cause was given precedence over a non-respiratory cause.

The number of deaths from respiratory causes at 16 weeks was estimated separately for the salmeterol, ipratropium bromide, and theophylline cohorts. Subjects who received one of the study drugs and did not die within 112 days of first use may have received another study drug subsequently. Such subjects could contribute person-time to more than one study cohort.

CHARACTERISTICS OF DRUG RECIPIENTS AND ASTHMA DRUG TREATMENT PRIOR TO THE INDEX DATE

In order to assess patient characteristics and indicators for the severity of asthma in the entire study population according to study drug, a detailed analysis of a random sample of 100 patients with at least 12 months of prior recorded drug use was performed for each of the three cohorts. Variables evaluated for each study drug cohort were (1) duration of asthma prior to the date of first prescription for a study drug (<12, 12-24, 25-60, >60 months, unknown), (2) the presence of other respiratory diagnoses in the patient history besides asthma (chronic obstructive pulmonary disease (COPD) or emphysema), (3) the number of outpatient visits $(0,1-4,>4)$ and whether or not the patient had been admitted to hospital due to asthma in the year prior to the index date, (4) the number of drug prescriptions for asthma in the year prior to the index date (in four three-monthly intervals), (5) drug treatment for asthma at the index date (no treatment, $\beta$ agonist, inhaled or oral steroid, $\beta$ agonist and steroid combined, other asthma drugs), (6) body mass index (BMI) $(<25,25-$ $29.9,30+\mathrm{kg} / \mathrm{m}^{2}$, unknown), and (7) smoking status (current, ex-smoker, non-smoker, unknown).

NESTED CASE-CONTROL ANALYSIS

To compare the risks of death in the three exposure groups a separate and independent nested case-control analysis was performed, adjusting for the above mentioned indicators of asthma severity. For this purpose, we identified the subjects who had died from a pulmonary cause (cases) and compared their drug exposure with that of a group of control patients derived from the base population who had survived. Cases were matched to six controls by age, sex, and calendar time (year of first prescription for a study drug). The same variables were assessed as those which were used to describe the entire base population (see above) and were included in the regression analysis. The control subjects for the nested case-control analysis were selected randomly from the base population (described above). Relative risk estimates (odds ratios), adjusted for the variables noted above, were obtained by conditional logistic regression (SAS).

\section{Results}

MORTALITY RATES FROM THE COHORT ANALYSIS A total of 14657 patients took part in the study, 6725 in the salmeterol group, 2937 in the ipratropium bromide group, and 2973 in the theophylline group who received a first time prescription for this one study drug only during the study period. In addition, 1135 subjects received a first time prescription for more than one study drug with an interval of more than 112 days, therefore contributing person-time to more than one drug group, and 887 subjects received a first time prescription for a second or third study drug within 112 days of the first time prescription of the first study drug.

A total of 8386 asthma patients contributed 112 days of follow up time of salmeterol use, 4305 patients of ipratropium bromide use, and 4228 of theophylline use. Since each patient was followed for four months, the salmeterol group represents 2795.3 person-years, the ipratropium group 1435 person-years, and the theophylline group 1409.3 person-years of follow up.

Overall, there were 70 deaths in the study population within 112 days of follow up after the first prescription of one of the three study drugs, $28(40 \%)$ of which were due to respiratory disease. The causes of death in the three drug groups, summarised according to categories (respiratory deaths, cardiovascular deaths, cancer deaths, other causes), are listed in table 1.

There were five deaths from respiratory disease in the salmeterol group (all men; one $<55$ 
Table 1 Causes of death (based on death certificates in all but two subjects)

\begin{tabular}{llllll}
\hline Cause of death & Salmeterol & $\begin{array}{l}\text { Ipratropium } \\
\text { bromide }\end{array}$ & Theophylline & $\begin{array}{l}\text { Mixed drug } \\
\text { treatment }\end{array}$ & Total \\
\hline Respiratory & 5 & 14 & 4 & 5 & 28 \\
Cardiovascular & 5 & 8 & 7 & - & 20 \\
$\quad$ Myocardial infarction & 4 & 4 & 3 & - & 11 \\
Heart failure & - & 4 & 3 & - & 7 \\
Cardiac arrest & 1 & - & - & - & 1 \\
$\quad$ Pulmonary embolism & - & - & 1 & - & 1 \\
Cancer & 5 & 7 & 2 & 1 & 7 \\
$\quad$ Lung cancer & 3 & 2 & 1 & 1 & 3 \\
Oesophageal cancer & - & 3 & - & - & 7 \\
Other cancer & 2 & 2 & 1 & - & 70 \\
Other causest & 2 & 1 & 3 & 1 & 7 \\
Total & 17 & 30 & 16 & 7 &
\end{tabular}

* More than one study drug started during the 16-week period of follow up (four deaths ipratropium bromide and theophylline, one death ipratropium bromide and salmeterol)

$t$ The cause of death was unascertainable for one subject in the salmeterol group. phylline; users of ipratropium were substantially older. The distribution of users by sex, BMI, and duration of asthma was also similar for the three groups. Users of ipratropium were less often current smokers, and users of salmeterol were less likely to have a concurrent diagnosis of COPD or emphysema $(5 \%)$ than users of theophylline $(15 \%)$ and ipratropium $(29 \%)$. The distribution of the number of outpatient visits for asthma in the year prior to use was similar in the three groups. However, admission to hospital for asthma in the year prior to use was more frequent in the ipratropium group (20\%) than in the salmeterol $(12 \%)$ and theophylline groups (6\%) (table 2$)$.

DRUG TREATMENT PRIOR TO INDEX DATE

Use of a $\beta$ agonist (77\%) prior to the index date was similar in the three groups (range $76-78 \%$; table 3). However, the use of inhaled steroids was higher in the salmeterol group $(93 \%)$ than in the theophylline $(73 \%)$ or ipratropium groups $(63 \%)$. In the three groups combined about $80 \%$ of subjects used at least two drugs for asthma prior to the index date. In the salmeterol group the percentage of patients receiving both a short acting $\beta$ agonist and steroids was higher $(77 \%)$ than for ipratropium bromide $(61 \%)$ and theophylline $(66 \%)$. The number of prescriptions for asthma drugs increased substantially during the 12 months prior to the index date (table 3 ). for users of salmeterol, ipratropium bromide and theophylline alone, respectively.

There were five cardiovascular deaths in the salmeterol group (crude death rate 1.8/1000 person-years), eight in the ipratropium bromide group (5.6/1000 person-years), and seven in the theophylline group (5.0/1000 person-years).

CHARACTERISTICS OF DRUG RECIPIENTS AND ASTHMA DRUG TREATMENT PRIOR TO THE INDEX DATE

The age distribution of the three study cohorts was similar for users of salmeterol and theo-

\section{CHARACTERISTICS OF DEATHS}

Of the subjects who died from a respiratory cause, 21 of $28(75 \%)$ had a prior diagnosis of COPD or emphysema. Demographic variables and indicators for the severity of asthma for the 28 respiratory deaths are described in table 4. The severity of the respiratory condition of the subjects who died compared with the three samples of 100 cohort subjects is reflected in a higher use of asthma drugs and a distinct

Table 2 Patient characteristics of the three cohorts

\begin{tabular}{|c|c|c|c|c|}
\hline Characteristic & Salmeterol & Ipratropium bromide & Theophylline & $p$ value $\left(\chi^{2}\right)$ \\
\hline \multicolumn{5}{|l|}{ Age (years) } \\
\hline $12-49$ & $5454(65.0 \%)$ & $1998(46.5 \%)$ & $2613(61.8 \%)$ & \\
\hline $50-64$ & $2932(35.0 \%)$ & $2307(53.5 \%)$ & $1615(38.2 \%)$ & $<0.001$ \\
\hline \multicolumn{5}{|l|}{ Sex } \\
\hline Male & $3497(41.7 \%)$ & $1834(42.6 \%)$ & $1818(43.0 \%)$ & \\
\hline Female & $4889(58.3 \%)$ & $2471(57.4 \%)$ & $2410(57.0 \%)$ & 0.33 \\
\hline \multicolumn{5}{|c|}{ Duration of asthma (months)* } \\
\hline$<12$ & $11 \%$ & $24 \%$ & $20 \%$ & \\
\hline $12-24$ & $10 \%$ & $9 \%$ & $10 \%$ & \\
\hline $25-60$ & $21 \%$ & $20 \%$ & $14 \%$ & \\
\hline $61+$ & $47 \%$ & $42 \%$ & $43 \%$ & \\
\hline Unknown & $11 \%$ & $5 \%$ & $13 \%$ & 0.24 \\
\hline \multicolumn{5}{|c|}{ COPD and/or emphysema } \\
\hline Yes & $5 \%$ & $29 \%$ & $15 \%$ & 0.001 \\
\hline \multicolumn{5}{|c|}{ Practitioner visits $\dagger$} \\
\hline 0 & $10 \%$ & $9 \%$ & $10 \%$ & \\
\hline $1-4$ & $50 \%$ & $41 \%$ & $50 \%$ & \\
\hline $5+$ & $40 \%$ & $50 \%$ & $40 \%$ & 0.60 \\
\hline \multicolumn{5}{|c|}{ Hospital admission } \\
\hline Yes & $12 \%$ & $20 \%$ & $6 \%$ & 0.012 \\
\hline \multicolumn{5}{|c|}{ Smoking status at index date } \\
\hline Current & $51 \%$ & $37 \%$ & $46 \%$ & \\
\hline Ex-smoker & $5 \%$ & $7 \%$ & $11 \%$ & \\
\hline Non-smoker & $7 \%$ & $18 \%$ & $10 \%$ & \\
\hline Unknown & $37 \%$ & $38 \%$ & $33 \%$ & 0.10 \\
\hline
\end{tabular}

Age and sex distributions represent the entire cohort. The other parameters represent a random sample of 100 subjects (absolute numbers are therefore percentages)

* Prior to the index date.

t Due to the respiratory disease in the 12 months prior to the index date. 
Table 3 Asthma drug treatment prior to the date of the first prescription for a study drug (index date)

\begin{tabular}{|c|c|c|c|c|c|c|c|c|}
\hline \multirow[t]{2}{*}{ Treatment } & \multicolumn{2}{|l|}{ Salmeterol } & \multicolumn{2}{|c|}{ Ipratropium bromide } & \multicolumn{2}{|c|}{ Theophylline } & \multicolumn{2}{|c|}{ Mixed drug treatment } \\
\hline & $\begin{array}{l}\text { Sample } \\
(n=100)\end{array}$ & $\begin{array}{l}\text { Deaths } \\
(n=5)\end{array}$ & $\begin{array}{l}\text { Sample } \\
(n=100)\end{array}$ & $\begin{array}{l}\text { Deaths } \\
(n=14)\end{array}$ & $\begin{array}{l}\text { Sample } \\
(n=100)\end{array}$ & $\begin{array}{l}\text { Deaths } \\
(n=4)\end{array}$ & $\begin{array}{l}\text { Sample } \\
(n=100)\end{array}$ & $\begin{array}{l}\text { Deaths } \\
(n=5)\end{array}$ \\
\hline No treatment & $5 \%$ & - & $12 \%$ & - & $15 \%$ & - & - & - \\
\hline$\beta$ agonist & $78 \%$ & $5(100 \%)$ & $76 \%$ & $14(100 \%)$ & $78 \%$ & $4(100 \%)$ & - & $5(100 \%)$ \\
\hline Inhaled steroid & $93 \%$ & $4(80 \%)$ & $63 \%$ & $11(79 \%)$ & $73 \%$ & $2(50 \%)$ & - & $4(80 \%)$ \\
\hline Oral steroid & $43 \%$ & $3(60 \%)$ & $44 \%$ & $10(71 \%)$ & $33 \%$ & $3(75 \%)$ & - & $4(80 \%)$ \\
\hline$\beta$ agonist plus steroid & $77 \%$ & $4(80 \%)$ & $61 \%$ & $14(100 \%)$ & $66 \%$ & $3(75 \%)$ & - & $5(100 \%)$ \\
\hline Other & $25 \%$ & $5(100 \%)$ & $6 \%$ & $14(100 \%)$ & $14 \%$ & $4(100 \%)$ & - & $5(100 \%)$ \\
\hline \multicolumn{9}{|c|}{$\begin{array}{l}\text { Mean no. of asthma drug prescriptions in the } 4 \times 90 \text { days prior to the index date } \\
\beta \text {-agonists }\end{array}$} \\
\hline $\begin{array}{l}\beta \text {-agonists } \\
360-271 \text { days }\end{array}$ & 1.8 & 3.6 & 1.3 & 4.0 & 1.5 & 2.5 & & 4.0 \\
\hline $270-181$ days & 1.7 & 4.8 & 1.4 & 4.1 & 1.7 & 3.0 & & 5.0 \\
\hline $180-91$ days & 1.9 & 5.2 & 1.4 & 3.5 & 1.8 & 3.0 & & 4.2 \\
\hline $90-1$ day & 2.2 & 9.4 & 2.3 & 3.1 & 2.4 & 4.3 & & 5.4 \\
\hline \multicolumn{9}{|l|}{ Steroids } \\
\hline $360-271$ days & 1.5 & 3.0 & 1.2 & 2.5 & 1.2 & 1.0 & & 3.2 \\
\hline $270-181$ days & 1.8 & 3.8 & 1.2 & 2.5 & 1.5 & 2.3 & & 4.8 \\
\hline $180-91$ days & 1.7 & 4.0 & 1.4 & 2.3 & 1.4 & 2.3 & & 3.8 \\
\hline $90-1$ day & 2.9 & 3.0 & 2.5 & 1.6 & 2.2 & 2.3 & & 3.8 \\
\hline \multicolumn{9}{|l|}{ Other asthma drugs } \\
\hline $360-271$ days & 0.4 & 1.8 & 0.2 & 0.7 & 0.1 & 0.5 & & - \\
\hline $270-181$ days & 0.5 & 3.0 & 0.2 & 1.2 & 0.1 & 0.8 & & - \\
\hline $180-91$ days & 0.6 & 3.8 & 0.2 & 1.5 & 0.1 & 1.3 & & 0.2 \\
\hline $90-1$ day & 0.5 & 4.6 & 0.3 & 2.1 & 0.2 & 2.5 & & 4.0 \\
\hline \multicolumn{9}{|l|}{ Total } \\
\hline $360-271$ days & 3.7 & 8.4 & 2.8 & 7.2 & 2.8 & 4.0 & & 7.2 \\
\hline $270-181$ days & 3.9 & 11.6 & 2.8 & 7.8 & 3.3 & 6.1 & & 9.8 \\
\hline $180-91$ days & 4.3 & 13.0 & 3.0 & 7.3 & 3.2 & 6.6 & & 8.2 \\
\hline $90-1$ day & 5.7 & 17.0 & 5.0 & 6.8 & 4.8 & 9.1 & & 13.2 \\
\hline
\end{tabular}

increase in the total number of asthma drug prescriptions in the four 90-day periods prior to the index date (table 3).

\section{NESTED CASE-CONTROL ANALYSIS}

Subjects who died of pulmonary causes were compared with those who survived. The controls were randomly selected from the base population and matched with the cases by age, sex, and calendar time (year of first prescription). Variables adjusted in a conditional logistic model were (1) number of prescriptions for asthma drugs in the three months prior to the index date, (2) number of outpatient visits in the prior 12 months, (3) whether or not the patient had been admitted to hospital due to asthma in the 12 months prior to the index

Table 4 Characteristics of the 28 deaths from respiratory causes

\begin{tabular}{|c|c|c|c|c|}
\hline & $\begin{array}{l}\text { Salmeterol } \\
(n=5)\end{array}$ & $\begin{array}{l}\text { Ipratropium } \\
\text { bromide } \\
(n=14)\end{array}$ & $\begin{array}{l}\text { Theophylline } \\
(n=4)\end{array}$ & $\begin{array}{l}\text { Mixed drug } \\
\text { treatment } \\
(n=5)\end{array}$ \\
\hline \multicolumn{5}{|l|}{ Age (years) } \\
\hline $12-49$ & 1 & 2 & - & 1 \\
\hline $50-64$ & 4 & 12 & 4 & 4 \\
\hline \multicolumn{5}{|l|}{ Sex } \\
\hline Male & 5 & 5 & 2 & 2 \\
\hline Female & - & 9 & 2 & 3 \\
\hline \multicolumn{5}{|c|}{ Duration of asthma (months) ${ }^{* *}$} \\
\hline$<12$ & - & 1 & 1 & - \\
\hline $12-24$ & - & 4 & - & - \\
\hline $25-60$ & 5 & 9 & 3 & 5 \\
\hline Unknown & - & - & - & - \\
\hline \multicolumn{5}{|c|}{ COPD and/or emphysema } \\
\hline Yes & 3 & 9 & 4 & 3 \\
\hline \multicolumn{5}{|c|}{ Practitioner visits } \\
\hline 0 & - & - & - & - \\
\hline $1-4$ & 2 & 3 & 1 & 1 \\
\hline $5+$ & 3 & 11 & 3 & 4 \\
\hline \multicolumn{5}{|c|}{ Hospital admission $\dagger$} \\
\hline Yes & 1 & 8 & 2 & - \\
\hline \multicolumn{5}{|c|}{ Smoking status at index date } \\
\hline Current & 1 & 3 & 1 & 2 \\
\hline Ex-smoker & 1 & 4 & 1 & - \\
\hline Non-smoker & - & 1 & 1 & - \\
\hline Unknown & 3 & 6 & 1 & 3 \\
\hline
\end{tabular}

* More than one study drug started during the 16-week period of follow up (four deaths ipratropium bromide and theophylline, one death ipratropium bromide and salmeterol). ** Prior to the index date.

tDue to the respiratory disease in the 12 months prior to the index date. date, and (4) current use of steroids prior to the index date. Smoking status, BMI, and duration of asthma were not included in the final model since they did not materially influence the risk estimates.

The adjusted relative risk estimates of ipratropium, theophylline, and multiple drug users compared with users of salmeterol were 7.9 (95\% CI 1.4 to 44.6$), 1.1$ (95\% CI 0.2 to 7.4 ), and 2.2 (95\% CI 0.3 to 17.5$)$, respectively.

The independent effects of other variables were derived from the conditional logistic model (using arbitrarily chosen and predefined categories for number of asthma drug prescriptions and number of practice visits). The relative risk estimate of those who had 10 or more asthma drug prescriptions compared with those who had four or fewer prescriptions, adjusted for study drug exposure, number of general practice visits, prior steroid use, and whether or not the patient had been admitted to hospital due to asthma in the year prior to the index date, was 67.2 (95\% CI 6.3 to 719.3$)$. The adjusted relative risk estimate was 6.2 (95\% CI 1.0 to 38.5 ) for subjects who had 10 or more visits to the general practice due to a respiratory complaint compared with those who had four or fewer visits in the year prior to the index date. One or more hospital admissions for respiratory illness in the year prior to the index date yielded an adjusted relative risk estimate of 47.0 (95\% CI 2.6 to 856.3) compared with those not admitted to hospital (table 5).

There were only seven cases with a diagnosis of asthma but not of COPD or emphysema (three in the ipratropium group, two in the salmeterol group, and two in the multiple drug exposure group). Because of the small number of cases without COPD, it was not possible to interpret a conditional logistic regression model controlling for the presence of the risk factor COPD. We therefore broke the matching and 
Table 5 Risk factors for respiratory mortality, controlled for drug exposure

\begin{tabular}{|c|c|c|c|c|}
\hline Risk factors & Cases & Controls & Odds ratio & $95 \% C I$ \\
\hline \multicolumn{5}{|c|}{ Number of asthma drug prescriptions** } \\
\hline$\leq 4^{*}$ & 6 & 106 & 1.0 & \\
\hline $5-9$ & 10 & 42 & 4.8 & 0.9 to 26.8 \\
\hline$\geq 10$ & 12 & 12 & 67.2 & $\begin{array}{l}6.3 \text { to } \\
719.3\end{array}$ \\
\hline \multicolumn{5}{|c|}{ Number of practice visits $\ddagger$} \\
\hline$\leq 4^{*}$ & 7 & 93 & 1.0 & \\
\hline $5-9$ & 8 & 53 & 1.1 & 0.2 to 4.7 \\
\hline$\geq 10$ & 13 & 14 & 6.2 & 1.0 to 38.5 \\
\hline \multicolumn{5}{|c|}{ Admissions to hospital for asthma } \\
\hline No* & 17 & 150 & 1.0 & \\
\hline Yes & 11 & 10 & 47.0 & $\begin{array}{l}2.6 \text { to } \\
856.3\end{array}$ \\
\hline \multicolumn{5}{|c|}{ Prior use of steroids** } \\
\hline No* & 2 & 36 & 1.0 & \\
\hline Yes & 26 & 124 & 0.7 & 0.1 to 5.5 \\
\hline
\end{tabular}

* Reference group.

* In the 3 months prior to the index date

$\ddagger$ In the 12 months prior to the index date

did an unconditional logistic regression analysis, restricted only to the 21 cases and 41 controls with COPD or emphysema. The age $(<55,55-59,60+$ years $)$ and sex adjusted relative risk estimates for first time users of ipratropium bromide, theophylline and multiple drug users compared with first time users of salmeterol were 1.8 (95\% CI 0.4 to 9.6 ), 3.0 (95\% CI 0.4 to 22.4 ), and 1.3 (95\% CI 0.2 to 9.6 ), respectively.

Further adjustment for number of drug prescriptions, number of practice visits, and whether or not the patient had been admitted to hospital in the year prior to the index date did not materially influence the results from this model.

\section{Discussion}

Based on the recommendations of the British Thoracic Society, ${ }^{4}$ a first time prescription for salmeterol, ipratropium bromide, or theophylline is indicated for patients with asthma which is not yet well controlled by a combination of a short acting $\beta$ agonist and an inhaled steroid. These guidelines led us to select patients treated for the first time with these drugs as comparison groups in our study. The results support the proposition that the three drugs were usually prescribed according to the guidelines. Eighty percent of the recipients were receiving at least two other antiasthma drugs prior to initiating additional treatment with one of the study drugs. The results also show that the addition of a study asthma drug to the prior treatment was regularly preceded by worsening of symptoms prior to initiation of the new drug therapy, as reflected in a considerable increase in the number of prescriptions for other asthma drugs in the preceding three months (table 3 ).

The results also show that the number of asthma drug prescriptions, the number of visits to general practice, and admission to hospital for respiratory problems in the year prior to the index date, as well as the presence of overlapping respiratory diseases such as COPD or emphysema, are strong independent predictors for pulmonary deaths in subjects with asthma in this study population (table 5).
An additional question addressed in the study was whether an asthma cohort treated with salmeterol has a higher respiratory mortality rate than a similarly severe asthma cohort treated with other asthma drugs. This question arises from the randomised 16-week follow up clinical trial conducted by Castle $e t a l^{1}$ which yielded a relative risk of 3.0 (95\% CI 0.7 to 20$)(\mathrm{p}=0.1)$ for deaths from asthma in salmeterol users compared with salbutamol users. Results from our nested case-control evaluation - after controlling for age, sex, calendar time, and other risk factors related to asthma severity - indicate that the death rate in salmeterol users is low and no higher than that for users of theophylline and ipratropium.

The randomised clinical trial of Castle et $a l^{1}$ and our observational study were similar with respect to some of the design characteristics. Both followed asthma patients who were newly treated with salmeterol for a 16week follow up period, both studies had comparison groups (salbutamol in the clinical trial, ipratropium bromide and theophylline in our study), and both accepted the clinical diagnosis made by the GP. However, a direct comparison of our results with the findings of the clinical trial needs some interpretation.

The clinical trial took place in 1990-1 and our study covered an observation period from 1992-5. Our study focused on patients thought to have more severe asthma, and there was likely to be somewhat fewer patients with "severe" asthma involved in the clinical trial than in our study. ${ }^{1}$ Many of the subjects in the clinical trial were judged by the general practitioner to have mild $(17 \%)$ or moderately severe $(65 \%)$ asthma. However, $91 \%$ were receiving a $\beta$ agonist, $69 \%$ an inhaled steroid, and $43 \%$ other drugs for asthma prior to initiation of a study drug. Thus, the severity of asthma in the clinical trial may not have been substantially different from that in our study. Finally, it is important to emphasise that in the clinical trial there were subjects who were over 64 years of age while our study included only subjects of less than 65 years of age.

We restricted our study to asthma patients below 65 years of age because younger subjects are more likely to have a firm and well documented diagnosis of asthma. Older patients are more likely to have overlapping pulmonary as well as cardiovascular diseases which can contribute to a deterioration of their respiratory condition.

The pulmonary mortality rates over a period of 16 weeks for patients in the clinical trial ${ }^{1}$ were $18 / 4704$ person-years (3.8/1000 personyears) for salmeterol treated patients and 4/ 2361 (1.7/1000 person-years) for salbutamol treated patients. In the current study the pulmonary mortality rate for salmeterol users was $5 / 2795$ person-years (1.8/1000 person-years), a rate which is similar to the mortality rate for salbutamol users in the clinical trial. This finding is consistent with the proposition that the threefold increased mortality in salmeterol users compared with salbutamol users observed in the clinical trial may have been a chance finding. Another possible explanation for the 
higher mortality rate among salmeterol users in the clinical trial compared with our study might be an increased awareness of doctors and patients of a delayed bronchodilatory effect of salmeterol compared with salbutamol. Inappropriate use of salmeterol rather than a short and fast acting bronchodilator during an acute asthma exacerbation as a "cause" of asthma mortality has been discussed elsewhere. ${ }^{1011}$

In summary, our study indicates that in the population studied salmeterol, theophylline, and ipratropium are regularly prescribed to previously treated asthma patients whose asthma was increasing in severity prior to the start of treatment with these three drugs. The 16-week mortality rate for pulmonary deaths was no higher in first time salmeterol users than in first time users of theophylline and ipratropium.

We thank the participating general practitioners for their excellent cooperation and Dr Alan Dean and his team for their enerous help. The Boston Collaborative Drug Surveillance Program is supported in part by the Food and Drug Administration, Cooperative Agreement FD-U-000071-15 and by grants from Astra AB, Berlex Laboratories, Bayer AG, Boots Healthcare International, Glaxo Wellcome Inc, Hoechst AG,
RW Johnson Pharmaceutical Research Institute, Novartis Pharmaceuticals, and Pfizer Inc. The current study has not been supported by any drug company.

Christoph Meier is supported in part by a grant from the "Swiss National Science Foundation" and the "Freiwillige Akademische Gesellschaft", Basel, Switzerland.

1 Castle W, Fuller R, Hall J, Palmer J. Serevent nationwide surveillance study: comparison of salmeterol with salbutamol in asthmatic patients who require regular bronchodilator treatment. BMF 1993;306:1034-7.

2 Bunney R. Study too small to detect increase in deaths (letter). BMF 1993;306:1610.

3 Sears MR, Taylor DR. Increased deaths during salmetero treatment unexplained (letter). BMF 1993;306:1610-1.

4 British Thoracic Society, National Asthma Campaign, Roya College of Physicians of London, et al. The British guidelines on asthma management: 1995 review and position statement. Thorax 1997;52(Suppl 1):S1-21.

5 Jick H, Jick SS, Derby LE. Validation of information recorded on general practitioner based computerised data resource in the United Kingdom. BMF 1991;302:766-8.

6 Jick H, Terris BZ, Derby LE, Jick SS. Further validation of information recorded on a general practitioner based computerized data resource in the United Kingdom. Pharmacoepidemiol Drug Safety 1992;1:347-9.

7 Jick H, Hall GC, Dean AD, Jick SS, Derby LE. A comparison of the risk of hypoglycemia between users of human and animal insulins. 1. Experience in the Unite Kingdom. Pharmacotherapy 1990;10:395-7.

8 Jick SS, Dean AD, Jick H. Antidepressants and suicide. BMF 1995;310:215-8.

9 Compendium of Health Statistics, 9th edn. London: Office of Health Economics, 1995.

10 Finkelstein FN. Risks of salmeterol (letter)? N Engl f Med 1994;331:1314

11 Palmer JBD, Rickard KA, Thompson JR. Reply to letter. N Engl f Med 1994;331:1314. 